\title{
Consequences of radioactive releases into the sea resulting from the accident at the Fukushima Dai-ichi nuclear power plant - Evolution of expert investigation according to the data available
}

\author{
P. LAGUIONIE ${ }^{1}$, P. BAILLY DU BOIS ${ }^{1}$, D. BOUST ${ }^{1}$, B. FIEVET $^{1}$, P. GARREAU $^{2}$,

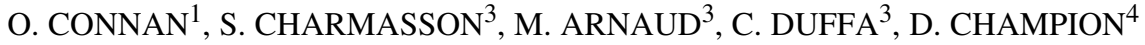

(Manuscript received 4 May 2012, accepted 16 July 2012)

ABSTRACT The accident at the Fukushima Dai-ichi Nuclear Power Plant (FDNPP) in March 2011 led to an unprecedented direct input of artificial radioactivity into the marine environment. The Institute for Radioprotection and Nuclear Safety was requested by the French authorities to investigate the radioecological impact of this input, in particular the potential contamination of products of marine origin used for human consumption. This article describes the close link between the responses provided and the availability of the data, as well as their nature and ability to meet the requirements of expert investigation. These responses were needed: (i) to evaluate the inputs of radionuclides into the marine environment, (ii) to understand their dispersion in seawater, and (iii) to estimate their transfer to the biota and sediments. Three phases can be distinguished which characterise these processes during the accident and post-accident periods. The first phase corresponds to an emergency phase during which no measurements were available on samples from the marine environment. It involved the formulation of hypotheses based solely on the expertise of the Institute for Radioprotection and Nuclear Safety. The second phase started when the Japanese authorities provided measurements of the concentrations of radionuclides in seawater. Although these data were not yet adapted to addressing the problems of radioecology, the scenarios could then be refined and the estimates developed in more detail. During the third phase, the accumulation of data over the course of time made it possible to study the phenomena in an appropriate way. The chronology of the events shows that it is essential to have (i) significant measurements of concentration from samples collected in the various matrices of the marine environment, regularly updated and sufficiently well-documented, (ii) samples of seawater collected at the earliest opportunity as close as possible to the damaged site to characterise the source term, and (iii) a numerical tool allowing rapid modelling

1 IRSN, Laboratoire de Radioécologie de Cherbourg-Octeville, rue Max Pol Fouchet, BP 10, 50130 Cherbourg-Octeville, France.

2 IFREMER, Laboratoire de Physique Hydrodynamique et Sédimentaire, Centre Bretagne, BP 70, 29280 Plouzané, France.

IRSN, Laboratoire d'Études Radioécologiques du Milieu Continental et Marin, Zone Portuaire de Bregaillon, BP 330, 83507 La Seyne-sur-Mer, France.

4 IRSN, Pôle Radioprotection-Crise, 31 avenue de la Division Leclerc, BP 17, 92262 Fontenay-aux-Roses, France. 
of the dispersion of radionuclides in seawater, as well as their transfer to sediments and the biota, ultimately for the purpose of estimating the dose to humans.

\section{Introduction}

On 11 March 2011, an earthquake of magnitude 9.0 occurred at 5h46 UT in the Pacific Ocean $\left(38.30^{\circ} \mathrm{N}, 142.50^{\circ} \mathrm{E}\right)$ to the east of the town of Sendai, Japan. At 6 h36 UT, a tsunami reached the Fukushima Dai-ichi nuclear power plant (FDNPP). A 15-m-high wave submerged the site, leading to the loss of the power generating units and the cooling systems. Consequently, the melting of the boiling water reactor cores, the venting of the containment buildings, the hydrogen explosions in the reactor buildings and the onset of boiling in certain pools gave rise to major releases of radioactive materials into the environment, involving the atmospheric and terrestrial compartments just as much as the marine compartments. The releases into the sea had three distinct origins: (i) contact of atmospheric radioactive aerosols with the water surface (deposition of aerosol particles and gaseous exchange at the interfaces), (ii) direct releases of radioactive water from the damaged FDNPP, whether or not in a controlled way, and (iii) runoff from river catchments following the leaching of soils by rainwater and the resurgence of subsoil waters. Direct fluxes of artificial radioactivity into the marine environment were without precedence. The principal input was derived from a fraction of the cooling waters (mostly seawater in this emergency situation) contaminated by the fuel, which then entered the sea. This scenario had not been taken into account for power generation plants. Following the Chernobyl accident in 1986, the marine environment (the Black Sea and Baltic and, to a lesser extent, the North Sea and English Channel) was impacted only by indirect atmospheric and riverine inputs.

In the context of an accident involving radioactive materials, the Institute for Radioprotection and Nuclear Safety (IRSN) has the role of assessing the risks entailed and providing technical expert reports to the French authorities. Its Emergency Response Centre was activated during the first six weeks after the beginning of the FDNPP accident. Given the extent and specificity of the releases into the sea, the IRSN issued an internal memorandum on 12 April 2011, setting up a Marine Support Unit with the following objectives: (i) compilation and analysis of the results of measurements of radionuclide concentrations in seawater, sediments and marine animals or plants collected off Japan, as well as (ii) the carrying out and utilisation of simulations of the dispersion of pollutants at sea and predictive estimates of the levels of contamination of food products of marine origin. These data should make it possible to establish, update and predict the state of the marine 
environment following the accident and make suitable recommendations in terms of radioprotection.

Faced with a catastrophe of this magnitude, the urgency of the responses that need to be provided evolves through the course of time. The protection of populations against atmospheric radioactive aerosols is a priority because the aerosol moves rapidly over great distances and can directly contaminate humans: it relies on a rapid simulation of atmospheric releases based on existing models and measurements carried out in situ with high limits of detection. The transfer of radioactive materials towards and within the marine compartment is taken into account in a subsequent stage. In the case of Fukushima, in the absence of a validated dispersion and transfer model, the development of suitable radioprotection measures depended mainly on the availability of in situ measurements. Since the urgency of the situation demanded rapid measurements on directly consumed samples, the available data were not well adapted to addressing the issues raised by the transfer of radioactive substances to these consumed samples, which include, for example, carrying out analyses on suspended particulate matter. Nevertheless, radioecology has a role of tracing the sources of the radionuclides and understanding their transfer processes in ecosystems, and as such, needs to provide responses based on data collected for purposes of radioprotection.

Within this framework, this article investigates the close link between the availability of the data and their nature and suitability to provide an adequate response in terms of the expert investigation and research following the accident at FDNPP. Starting from a non-exhaustive history of the work carried out by the Marine Support Unit of the IRSN (2011a, 2011b), it is possible to draw some lessons from the accident and post-accident periods. In particular, three phases are distinguished. The first phase, from 11 to 20 March 2011, is characterised by the absence of in situ measurements, which led to the formulation of hypotheses based solely on the expertise of the IRSN and the literature data. The second phase, from 21 March to 28 April 2011, started when the first data on the concentration of radionuclides in seawater were made available to the international community. The initial scenarios could then be re-assessed and, at the same time, the responses given in terms of modelling had to be formulated based on data dedicated to radioprotection. Finally, once the releases were stabilised and the statistical analysis of the data had been expanded, it became possible to understand the phenomena in a more rigorous way (the third phase, from 29 April to 31 October 2011) and achieve a better grasp of the impact from the point of view of radioprotection. Following the third phase, discussions are now focused on research programmes that need to be undertaken to fill the identified gaps in our scientific knowledge. 
These three phases make up the main subject matter of the present study, which highlights the importance of collecting samples and making them available to the scientific community in accident situations. The availability of these measurements enabled the IRSN to address questions about the qualification and the quantification of the marine source term (total radioactivity introduced into the marine environment), as well as the dispersion of radionuclides in water (firstorder transport vector) and, ultimately, the transfer of radionuclides to matrices making up the marine compartment (second-order transport vector), such as biota (marine fauna and flora) intended for human consumption.

\section{Phase 1: formulating hypotheses in the absence of data}

\subsection{Definition of phase 1 (11-20 March 2011)}

The first phase (11-20 March 2011, Fig. 1) is defined by the absence of any concentration data for radionuclides in the marine environment. During this period, efforts were initially focused on characterising the radioactive releases and estimating displacements and atmospheric transfer processes with fast kinetics liable to produce an immediate major radiological impact. Nevertheless, contamination of the water was also expected in the short term because of the proximity of the plant to the coast and the prevailing offshore wind direction. Consequently, some information was rapidly required on the potential contamination of seafood products destined for human consumption. In the absence of data, it was necessary to consider scenarios involving the transfer of radionuclides from seawater to the biota. These scenarios, which are described in the following section, would thus implicitly influence the definition of the marine source term and the dispersion of radionuclides in seawater.

\subsection{Source term}

The point of departure for any radioecological study is the knowledge of the source term. During the first few days following the accident, the two main sources of radionuclides entering the sea were represented by atmospheric inputs followed by direct liquid releases from the damaged FDNPP, with some inputs being supplied at a later stage from catchment areas (involving processes with slower kinetics). These probable inputs from the catchments were not identified during the months following the accident, since their impact was weaker than the first two sources. Hypotheses and first estimates had to be formulated for these two main sources.

The emission of radioactive aerosols from FDNPP into the atmosphere mainly occurred during 3 events that took place on 12 and 13 March with a south-westerly 


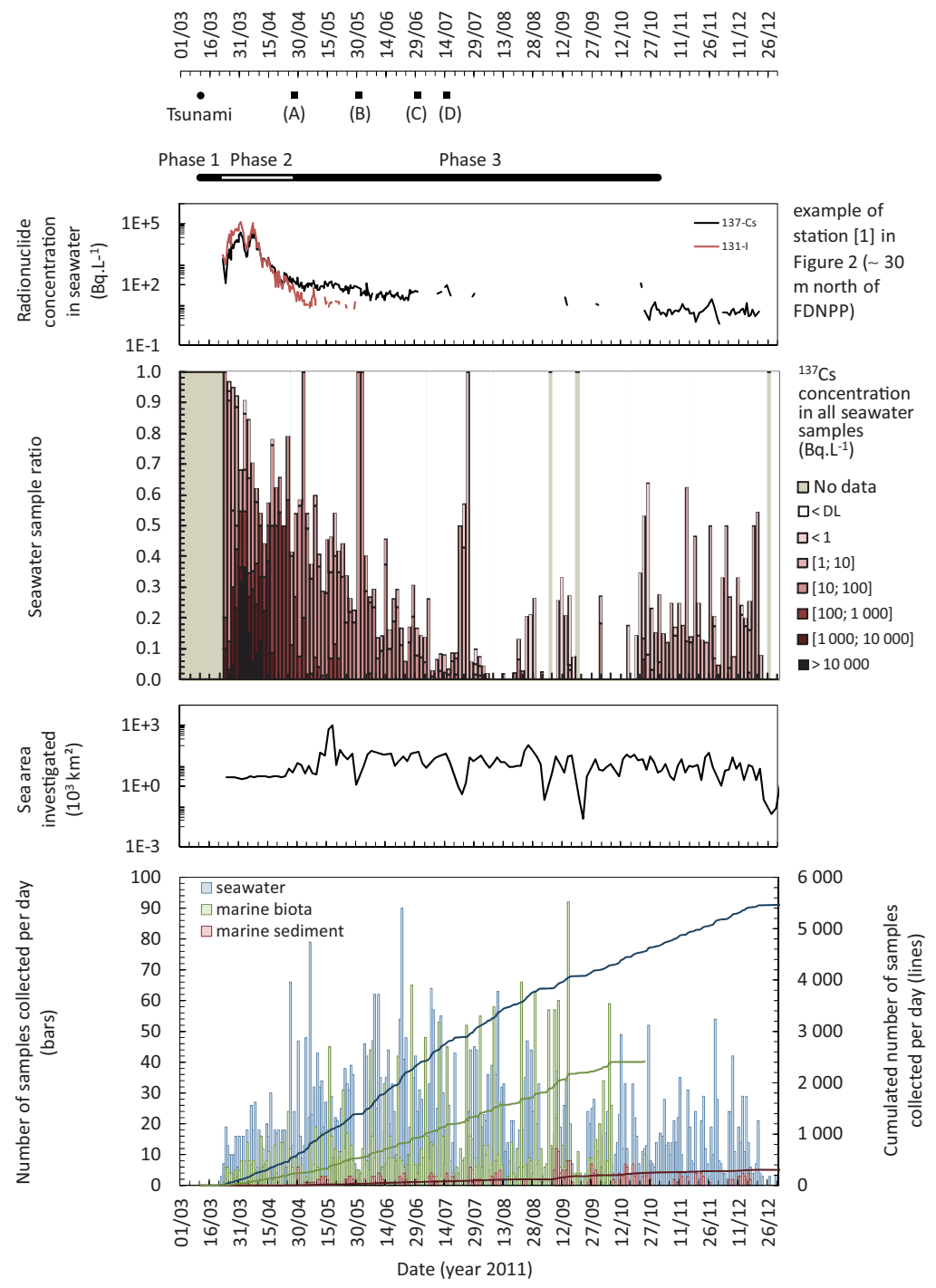

Figure 1 - Statistics of samples collected up until 31 December 2011 (seawater, sediments and biota), marine area covered by sampling, statistics of the results of measurement of ${ }^{137} \mathrm{Cs}$ concentration in seawater, chronology of monitoring of the ${ }^{137}$ Cs concentrations in seawater nearest to FDNPP, and main results obtained from research and expert study: (A) first estimation of the source term and delimitation of the zones of exceedance of the Maximum Permissible Concentration (MPC) in fish, (B) kinetic modelling of the transfer of radioactivity to fish, $(C)$ physical modelling of dispersion and $(D)$ updating of the source term. 
wind and on March 15 with a wind turning from northerly to southerly. In the case of a nuclear power plant still operating at the time of the accident, the atmospheric emissions will be primarily composed of isotopes of xenon, iodine, tellurium and caesium. The signature is defined by the concentration ratios between the radionuclides making up these emissions. Because of the quantities released and the mode of transfer of these radionuclides, in particular iodine, the dosimetric impact is particularly important during the first few weeks following the accident. After several years, especially radio-caesium will be detectable in the environment, in particular ${ }^{137} \mathrm{Cs}$, whose half-life is 30.15 years. This is why this radionuclide is often taken as an example for assessments of radioactivity. The dispersion of the radioactive aerosols and their contribution to the contamination of the marine environment was modelled by the IRSN using the software pX. In the case of ${ }^{137} \mathrm{Cs}$, the total atmospheric input to the marine environment within an 80-km radius from FDNPP is estimated at $7.6 \times 10^{13} \mathrm{~Bq}$ (Bailly du Bois et al., 2011). This corresponds to the sum of the inputs from the events of 12,13 and 15 March, leading to dry and wet deposition on the sea surface to the north-east of FDNPP and on a coastal strip to the south of FDNPP.

Concerning the direct releases into the sea, experimental data were used to evaluate the order-of-magnitude distribution of radionuclides contained in waters that were in contact with the fuel, but the physicochemical form of each radionuclide is not known. The IRSN calculated an inventory of approximately 500 radionuclides that are likely to be released from a damaged reactor. After eliminating certain elements already released in gaseous form and those with very short half-lives (order of magnitude of a second), some hundreds of radionuclides that normally never reach the marine environment can be identified as liable to contribute to the potential contamination of biota, seawater and sediment (Schiermeier, 2011). About fifty radionuclides (gamma-emitters for the most part) are then assumed to be detectable in seawater up to 15 days after the release, at concentrations ranging from 1 to $1000 \mathrm{~Bq} \cdot \mathrm{L}^{-1}$, yielding a total activity of about $10000 \mathrm{~Bq} \cdot \mathrm{L}^{-1}$ (Schiermeier, 2011). These radionuclides correspond to 30 chemical elements that are expected to exist in a wide variety of forms in the contaminated marine environment.

However, seawater sampling near this site was required to quantify the total radioactivity of the direct liquid releases and draw up a precise inventory of the radionuclides transported during this period. Indeed, concentrations of radionuclides with half-lives of less than a few hours fell rapidly beneath the limit of detection in seawater. However, because of the released fluxes, these short-lived radionuclides account for most of the dose received by the biota near FDNPP in the short term (Buesseler et al., 2011; Garnier-Laplace et al., 2011). 


\subsection{Dispersion in seawater}

It is essential to predict the dispersion-dilution of the radionuclides in the marine environment to target the zones at risk of contamination. During the first phase, in the absence of hydrodynamic dispersion models for this area, the dispersion scenario was based mainly on a literature search to establish the hydrodynamic context near FDNPP.

The FDNPP is located on the east coast of the island of Honshu, $200 \mathrm{~km}$ northeast of Tokyo. The coast runs north-south, facing the Pacific Ocean. The water depth increases steadily offshore, reaching some $200 \mathrm{~m}$ at $50 \mathrm{~km}$ from the coast; it then increases suddenly to $5000 \mathrm{~m}$ beyond about $100 \mathrm{~km}$. Schematically, the considerable water depths associated with weak tidal currents lead to limited vertical exchanges and, consequently, a stratification of the water masses. Thus, the radionuclides entering the marine environment at the sea surface will be contained and dispersed in a mixed layer approximately $20-50 \mathrm{~m}$ thick a few $\mathrm{km}$ from the coast. The thickness of this layer can reach approximately $100 \mathrm{~m}$ further offshore (Mercator Ocean ${ }^{5}$ ).

Near FDNPP, the mechanisms of dispersion of radionuclides in surface waters involve tidal currents, wind shear on the sea surface and the local impact of the general circulation of Pacific water masses. In the short term, the effects of the tide and the wind are predominant. The tide generates a back-and-forth motion of the water masses to the north and south along the coast, with speeds of about $1 \mathrm{~m} \cdot \mathrm{s}^{-1}$ and a periodicity of approximately $12 \mathrm{~h}$. Wind primarily influences the circulation of surface waters on variable scales in time and space. The circulation of the water masses is also influenced by the interaction of the warm Kuroshio ocean current, which comes from the south, skirting the coasts of Japan, and the cold Oyashio current, which comes from the north (Hycom ${ }^{6}$ simulations). The coastal waters near FDNPP are located in a zone of convergence and interaction between these two currents, thus creating mixing eddies. These unstable swirling structures to the east of FDNPP mix surface waters between latitudes $35.50^{\circ} \mathrm{N}$ and $38.50^{\circ} \mathrm{N}$ and, consequently, will have a determining impact on the medium-term dispersion of the radionuclides. The whole or part of the coastal zones located between these latitudes is likely to be impacted by the dispersion of radioactive pollution. In the long term, the surface water will migrate towards the south, but probably no farther than the latitude of Tokyo $\left(35.40^{\circ} \mathrm{N}\right)$. The Kuroshio current will then carry the plume towards the centre of the Pacific. Long-range dispersion will mainly concern the radionuclides with medium to long half-lives such as ${ }^{134} \mathrm{Cs}$ and ${ }^{137} \mathrm{Cs}$ and

\footnotetext{
5 Mercator Ocean, http://www.mercator-ocean.fr/eng.

6 Hycom, http://hycom.org/.
} 
potentially the plutonium isotopes (half-lives of several thousands of years for ${ }^{239} \mathrm{Pu}$ and ${ }^{240} \mathrm{Pu}$ ). On a global scale, and as an example, the transit time of ${ }^{137} \mathrm{Cs}$ from the north-western Pacific to the equatorial Pacific is estimated at 10-15 years, while it is less than 40 years from the Northern Pacific to the South Atlantic (Aoyama and Hirose, 2003; Sanchez-Cabeza et al., 2011).

\subsection{Transfer to sediments and biota}

The distribution of the concentrations of radionuclides in seawater represents the input data for estimating their transfer to the sediments and biota. Radionuclides with a half-life of less than a few tens of days should no longer be detected at significant levels after a few months, and will have no long-term impact on the marine environment at long distances. On the other hand, this will not be the case for ${ }^{106} \mathrm{Ru}$ (half-life of 372.6 days), ${ }^{134} \mathrm{Cs}$ (half-life of 2.066 years), ${ }^{137} \mathrm{Cs}$, or the plutonium isotopes.

Dispersed within the marine environment, these radionuclides are distributed in various proportions among the aqueous, mineral and organic phases. For example, studies carried out on Pu-isotopes introduced into the Pacific following atmospheric nuclear tests (late 1950s and early 1960s) showed that their apparent half-lives in Pacific surface waters varied from 5 to 12 years according to the studied zones (Povinec et al., 2005). The fact that the apparent half-lives are shorter than the radioactive half-lives reflects the existence of a process of extraction of the radionuclides from the aqueous phase by the biota and immobile particles.

An estimation is required of the transfer of radionuclides to the biota in order to restrict - if necessary - the consumption of certain seafood products that are considered to be excessively contaminated. However, this estimate is ultimately insufficient to calculate the dose to humans. Indeed, the estimation of radionuclide transfer is made complex by many parameters. For example, it is difficult to obtain information about the origin of the products: i.e. local versus imported produce, fishing versus aquaculture, or even the list of consumed species. In the absence of data, it is only possible to consider a scenario of transfer from the aqueous phase to the biota under steady-state conditions. When a living organism is exposed to a constant level of contamination for several months, the concentration of a given radionuclide can be estimated from the concentration of this radionuclide in water and the concentration factor $\mathrm{CF}$ (ratio between mass concentration in a living species and seawater, on a fresh weight basis). There is a specific value of $\mathrm{CF}$ for each element and each phylum (IAEA, 2004). The CF can vary from a value of ten to a few thousands according to the radionuclide and the species in question, in particular as a function of its metabolism. For example, the concentration factors for caesium are 60 for molluscs (except cephalopods), 50 for brown algae seaweed 
and 100 for fish (IAEA, 2004). In the case of iodine, the CF values are 10 for molluscs (except cephalopods), 10000 for brown algae seaweed and 9 for fish (IAEA, 2004). In the short term, it is not out of the question that ${ }^{131}$ I (half-life of 8.02 days) could contaminate the brown seaweed that is cultivated intensively in Japan. The total activity of gamma-emitting radionuclides in the biota was estimated as reaching $10^{4}$ to $10^{5} \mathrm{~Bq} \cdot \mathrm{kg}^{-1}$ fresh weight in fish and $10^{2}$ to $10^{8} \mathrm{~Bq} \cdot \mathrm{kg}^{-1}$ fresh weight in seaweed (Schiermeier, 2011). Subsequently, the decrease in contamination of seafood products will follow the same pattern as that observed in water, over a duration depending on the biological half-life of the living organisms according to the radionuclide considered.

In addition, biota contributes to the formation of sedimentary deposits, along with terrigenous particles derived from the river catchments. The presence of radionuclides in sedimentary deposits depends not only on the rate of sedimentation of contaminated particles (organic and mineral), but also on the capacity of the bottom sediments to adsorb the dissolved chemical species. Thus, fine sediments are more effective in adsorbing contaminants because of their large specific surface area. In a first approach, the distribution of the radionuclides between the water and the sedimentary particles is generally estimated by the partition coefficient

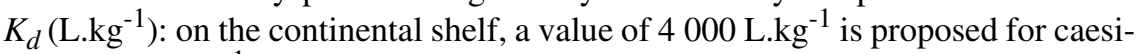
um and $70{\mathrm{~L} . \mathrm{kg}^{-1}}$ for iodine (IAEA, 2004). "Hot" particles may also be present in the sedimentary deposits, corresponding to irradiated material or fuel fragments activated in the reactor as they passed close to the core. The total activity of gamma emitters in the sedimentary deposits has been estimated as reaching $10^{4}$ to $10^{7} \mathrm{~Bq} \cdot \mathrm{kg}^{-1}$ dry weight (Schiermeier, 2011). In the long term, the sediments will continue to represent a diffuse and time-delayed source of contamination for the water column and living organisms.

Without any measurements of the concentration of radionuclides in samples of seawater, biota or sediments, the expert study is limited by the hypotheses and estimates summarised above.

\section{Phase 2: carrying out an expert study based on the first available data}

\subsection{Definition of phase2 (21 March-28 April 2011)}

Once the risks of contamination by releases into the atmosphere had declined, the question arose of potential indirect contamination. In the marine environment, responses were expected on the presence of radionuclides in fishery products, which therefore indirectly concerned the processes of radionuclide transfer from the aqueous phase to the biota and sediments. During the second phase, the expert 
study was based on the first data of radionuclide concentrations in seawater, which were posted online as from 21 March 2011 by the Tokyo Electric Power Company $\left(\mathrm{TEPCO}^{7}\right)$ and the Japanese Ministry of Education, Culture, Sports, Science and Technology $\left(\mathrm{MEXT}^{8}\right)$. Although the radioactive releases were not stabilised and the sampling protocol was not well adapted, a radioecological approach was implemented to estimate the dispersion of the radionuclides and the marine source term. This second phase ended on 28 April 2011 with the response of the IRSN to the request of the Ministry for Agriculture, Food, Fisheries, Rural Affairs and Regional Planning, in relation to fishery products in the Pacific. The estimates carried out and the methods adopted to meet that objective are presented below.

The in situ processes take place according to the following chronology: inputs to the marine environment, then dispersion in seawater and, finally, transfer to the biota. However, in practice, the adopted approach required an initial interpretation of the measurements of dispersion, which were then used to estimate the upstream inputs and transfers to the biota.

\subsection{Data available}

Since seawater represents the main transport vector for the radionuclides, it was the first matrix to be sampled as from 21 March 2011 to measure the concentration of radionuclides. The sampling of living organisms began two days later with the fish species, Beryx splendens. No sediment sampling was carried out during this second phase.

Up until 28 April 2011, a total of 580 seawater samples were collected near FDNPP by Japanese organisations. Initially, the investigated marine area was restricted to approximately $3000 \mathrm{~km}^{2}$ around the site (between longitudes $141.01^{\circ} \mathrm{E}$ and $141.41^{\circ} \mathrm{E}$, and latitudes $36.99^{\circ} \mathrm{N}$ and $37.75^{\circ} \mathrm{N}$ ). The sampling was limited by the human and material resources available, and the urgency of the situation, and was therefore carried out assuming a strong dilution of the radioactivity. From 25 April, the sampling zone was extended towards the south as far as latitude $35.75^{\circ} \mathrm{N}$, on a transect whose orientation was probably dictated by the drift of the water masses. The surface sampling was carried out mainly at 14 monitoring stations: 4 were located close to the coast (the nearest being $30 \mathrm{~m}$ to the north of FDNPP), 6 at $15 \mathrm{~km}$ and 4 at $30 \mathrm{~km}$ (Fig. 2). The distribution and number of stations made it possible to monitor the released fluxes and estimate the dispersion of the radionuclides at a high-resolution time step ( $12 \mathrm{~h}$ on average for the stations nearest to FDNPP).

7 TEPCO, http://www.tepco.co.jp/en/index-e.html.

8 MEXT, http://www.mext.go.jp/english/. 


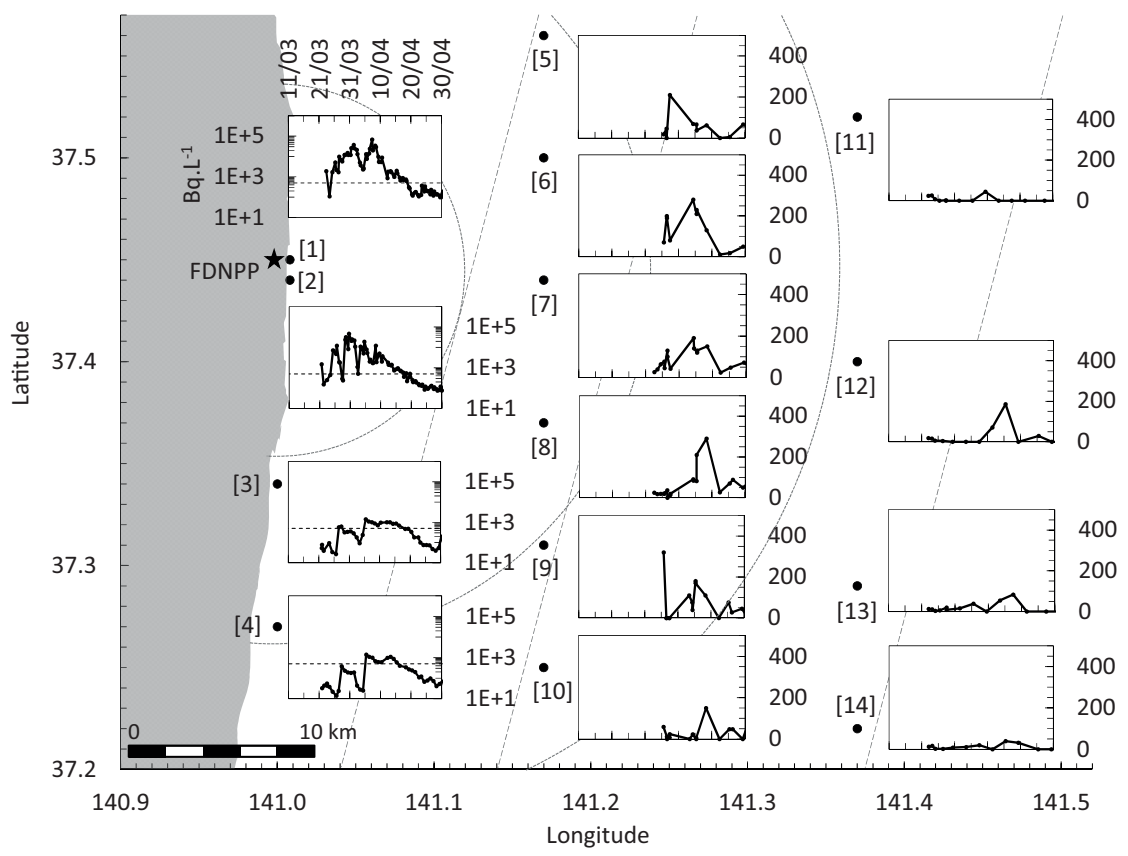

Figure 2 - Concentrations of ${ }^{137}$ Cs in seawater up until 28 April 2011 at the 14 main monitoring stations located near FDNPP.

Measurements of radionuclide concentrations in seawater detected the presence of 16 gamma-emitting radionuclides between the 21 and 31 March 2011 (Fig. 3). This number of radionuclides is lower than that expected 10 to 20 days after the accident, as had been predicted during the first phase. Three hypotheses, which are not mutually exclusive, can explain this result: (i) not all the radionuclides, in particular the alpha- and beta-emitters, were targeted by the measurements, (ii) ten days after the accident, the radionuclides with very short half-lives had concentrations lower than the detection limit (DL), and (iii) the processes of transfer and dissolution of the fuel are specific to each radionuclide. Moreover, even if the number of detected radionuclides proved to be low, their concentrations were themselves higher than the expected levels: 7 radionuclides were present at mean concentrations higher than $1000 \mathrm{~Bq} \cdot \mathrm{L}^{-1}\left({ }^{140} \mathrm{Ba},{ }^{134} \mathrm{Cs}\right.$, ${ }^{137} \mathrm{Cs}$, ${ }^{131} \mathrm{I},{ }^{132} \mathrm{I},{ }^{129} \mathrm{Te}$ and ${ }^{129 \mathrm{~m}} \mathrm{Te}$ ). From March 31 , only data on radionuclides with half-lives longer than 8 days were made available (Fig. 3). The communicated results were focused mainly on three radionuclides: ${ }^{131} \mathrm{I},{ }^{134} \mathrm{Cs}$ and ${ }^{137} \mathrm{Cs}$.

During this second phase, the concentrations in seawater were higher than those measured immediately after the accident. Up to $36 \%$ of the measured concentrations 


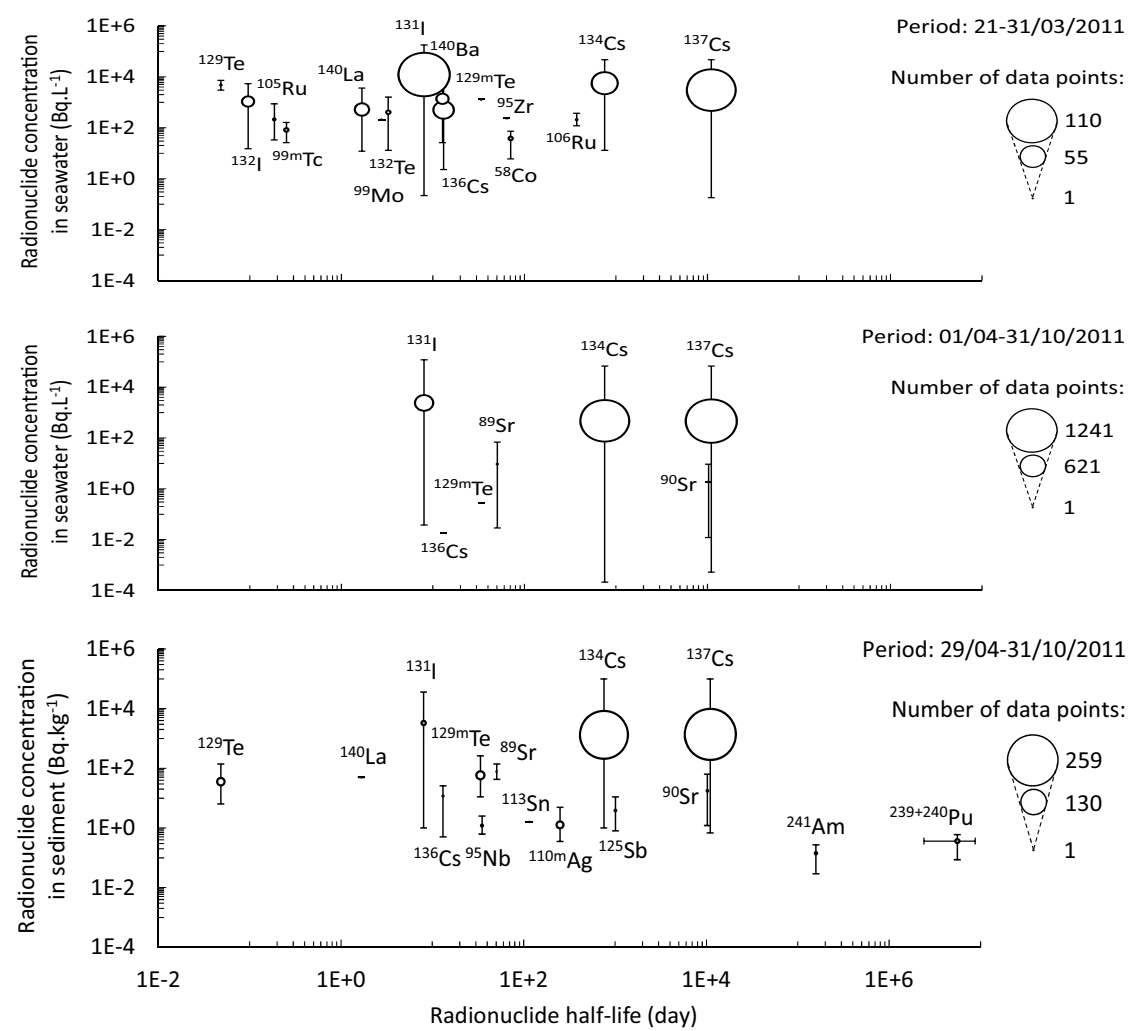

Figure 3 - Inventory of radionuclides measured in seawater (periods from 21 to 31 March 2011 and from 1 st April to 31 October 2011) and in sediments (period of 29 April to 31 October 2011).

of ${ }^{137} \mathrm{Cs}$ (2 March-31 April) show values higher than 10000 Bq.L ${ }^{-1}$ (Fig. 1). In a general way, ${ }^{131} \mathrm{I},{ }^{134} \mathrm{Cs}$ and ${ }^{137} \mathrm{Cs}$ show the strongest concentrations. On the basis of the available data, these radionuclides make up the main proportion of the total radioactivity present in the marine environment in the short and medium term. Consequently, ${ }^{131} \mathrm{I},{ }^{134} \mathrm{Cs}$ and ${ }^{137} \mathrm{Cs}$ are the only radionuclides to be measured routinely on the collected samples because they were the dominating components of the dose. These three radionuclides are gamma-emitters that can be easily measured, showing concentrations and half-lives making it possible to envisage monitoring in the short and medium term $\left({ }^{134} \mathrm{Cs}\right.$ and $\left.{ }^{137} \mathrm{Cs}\right)$ with high DLs. The example of ${ }^{137} \mathrm{Cs}$ shows that $67 \%$ of the measurements yielded significant results ( $>$ DL) during this second phase. On the other hand, this strategy allowed only a partial assessment of the activities present in the marine ecosystems. 


\section{CONSEQUENCES OF RADIOACTIVE RELEASES INTO THE SEA}

The results display considerable variability in time and space. In particular, ${ }^{131}$ I reached a maximum value of $180000 \mathrm{~Bq} . \mathrm{L}^{-1}$ in a sample collected on 30 March 2011 near the coast $330 \mathrm{~m}$ south of FDNPP (station [2], Fig. 2). The maximum values of ${ }^{134} \mathrm{Cs}$ and ${ }^{137} \mathrm{Cs}$ (67 000 and $68000 \mathrm{~Bq} \cdot \mathrm{L}^{-1}$, respectively) were measured on 7 April near the coast 30 m north of FDNPP. The maximum values for ${ }^{131} \mathrm{I},{ }^{134} \mathrm{Cs}$ and ${ }^{137} \mathrm{Cs}$ can be compared against the median values over the duration of phase 2, which are 100, 125 and $130 \mathrm{~Bq} . \mathrm{L}^{-1}$, respectively. These median values are lower by three orders of magnitude than the maximum values. At $30 \mathrm{~km}$ off the coast, the temporal evolution of the concentrations showed a minimum on 30 March 2011. At this station, before 30 March 2011, the concentrations probably result from atmospheric deposition, with levels ranging between 2 and $27 \mathrm{~Bq} . \mathrm{L}^{-1}$ for ${ }^{137} \mathrm{Cs}$ and between 3 and $57 \mathrm{~Bq} . \mathrm{L}^{-1}$ for ${ }^{131} \mathrm{I}$. Water sampling was also carried out at depth (150 $\mathrm{m}$ on average), and sometimes at an intermediate level between the bottom and the sea surface. The mean ratio of concentrations between surface and bottom samples is 3.9, while for the intermediate and surface samples, the ratio is 1.2 . These results highlight the inhomogeneity of the concentration profiles (in the case of ${ }^{131} \mathrm{I},{ }^{134} \mathrm{Cs}$ and ${ }^{137} \mathrm{Cs}$ ), which is consistent with the presence of a mixing layer at water depths ranging between 80 and $800 \mathrm{~m}$ (average of $260 \mathrm{~m}$ ).

In addition to the data on the radionuclide concentrations in seawater, measurements carried out on the biota (restricted to fishery products) showed variations in concentration reaching several orders of magnitude between individuals of the same species landed at the same port (for example, Ammodytes personatus landed at Iwaki). However, the absence of any indication on the fishing zones limited the interpretation of these data.

At a general level, the collected data needed to be treated with caution due to the absence of information on the sampling conditions, and the conditioning and treatment of the samples, as well as the counting techniques employed.

\subsection{Validation of the dispersion scenario in water}

Based on the measurements of radionuclide concentrations in seawater, the dispersion scenario proposed during the first phase was validated. A strong gradient of decreasing concentrations is observed from west to east (Fig. 2). Overall, the highest concentrations were measured near the site of FDNPP (measurements available $30 \mathrm{~m}$ to the north of the site). These concentrations decrease sharply with distance because of dilution. In addition, coastal radioactive pollution advanced several tens of km towards the south and probably also towards the north because of oscillating tidal currents parallel to the coast. 
Published data on marine source terms.

\begin{tabular}{|c|c|c|c|c|c|c|c|c|}
\hline \multirow[b]{2}{*}{ References } & \multirow[b]{2}{*}{ Method } & \multicolumn{3}{|c|}{ Direct liquid release into the sea } & \multicolumn{4}{|c|}{ Deposition on water surface } \\
\hline & & $\begin{array}{c}{ }^{137} \mathrm{Cs} \\
\left(10^{15} \mathrm{~Bq}\right)\end{array}$ & $\begin{array}{c}{ }^{131} \mathrm{I} \\
\left(10^{15} \mathrm{~Bq}\right)\end{array}$ & ${ }^{131} \mathrm{I} /{ }^{137} \mathrm{Cs}$ & $\begin{array}{l}\text { Coverage } \\
(\mathrm{km} \times \mathrm{km})\end{array}$ & $\begin{array}{c}{ }^{137} \mathrm{Cs} \\
\left(10^{15} \mathrm{~Bq}\right)\end{array}$ & $\begin{array}{c}{ }^{131} \mathrm{I} \\
\left(10^{15} \mathrm{~Bq}\right)\end{array}$ & ${ }^{131} \mathrm{I} /{ }^{137} \mathrm{Cs}$ \\
\hline $\begin{array}{l}\text { NERH } \\
(2011)\end{array}$ & $\begin{array}{l}\text { Calculated from leakage } \\
\text { flow rate from breach }\end{array}$ & 0.94 & $18.7^{*}$ & 19.9 & & & & \\
\hline $\begin{array}{l}\text { Kawamura } \\
\text { et al. } \\
\text { (2011) }\end{array}$ & $\begin{array}{l}\text { Comparison } \\
\text { with SEA-GEARN } \\
\text { model - measurements } \\
\text { at sea }\end{array}$ & 4 & 11 & 2.8 & $(1700 \times 1700)$ & 5 & 57 & 11.4 \\
\hline $\begin{array}{l}\text { Tsunume } \\
\text { et al. } \\
\text { (2011) }\end{array}$ & $\begin{array}{l}\text { Comparison } \\
\text { with ROMS model - } \\
\text { measurements at sea }\end{array}$ & $3.5 \pm 0.7$ & & & & $\begin{array}{l}\text { Less than } \\
\text { direct } \\
\text { release }\end{array}$ & & \\
\hline $\begin{array}{l}\text { Bailly du } \\
\text { Bois et al. } \\
(2011)\end{array}$ & $\begin{array}{l}\text { Quantities derived from } \\
\text { measurements at sea and } \\
\text { dilution }+ \text { simulation } \\
\text { model (pX) }\end{array}$ & $\begin{array}{c}27 \\
(12-41)\end{array}$ & $540^{*}$ & 20 & $(50 \times 100)$ & 0.0076 & $0.1^{*}$ & 14 \\
\hline
\end{tabular}

* Values corrected for decay as from 11 March 2011, in cases where communicated information was sufficient.

\subsection{First estimation of the marine source term}

Once the discharge rate became stabilised, as indicated by the temporal monitoring of ${ }^{131} \mathrm{I},{ }^{134} \mathrm{Cs}$ and ${ }^{137} \mathrm{Cs}$ concentrations between 20 and 27 April close to FDNPP (monitoring station [1] in Fig. 2), the source term could be estimated from the dispersion scenario described above. Indeed, it was then possible to map the isoconcentration contours for each radionuclide starting from the mean values of measurements obtained over this period. Moreover, using the assumptions derived from the dispersion scenario (i.e.: homogeneous concentration in the uppermost $50 \mathrm{~m}$ of the water column, homogeneous concentration gradient from the coast towards the open sea and effect of non-renewal of water masses on the calculation), the quantities introduced into the sea following the accident could be estimated by volume integration of the concentrations. This first estimation of the source term by the IRSN yielded: $5.7 \times 10^{15} \mathrm{~Bq}$ for ${ }^{137} \mathrm{Cs}, 5.7 \times 10^{15} \mathrm{~Bq}$ for ${ }^{134} \mathrm{Cs}$ and $3.3 \times 10^{15} \mathrm{~Bq}$ for ${ }^{131} \mathrm{I}$. It is noteworthy that these values were probably underestimated since water is renewed and that a fraction of the radionuclides was detected by measurements at depths shallower than $50 \mathrm{~m}$.

The source-term estimate of $5.7 \times 10^{15} \mathrm{~Bq}$ obtained for ${ }^{137} \mathrm{Cs}$ is two orders of magnitude higher than the value of $7.6 \times 10^{13} \mathrm{~Bq}$ derived from the modelling of deposition on the sea surface (Bailly du Bois et al., 2011), suggesting that direct liquid releases from FDNPP represent the main source of radionuclides in the marine environment. Only part of this $5.7 \times 10^{15} \mathrm{~Bq}$ source term, which is not easily quantifiable from in situ measurements, can be attributed to atmospheric inputs, as implied by the concentrations measured before the end of March $30 \mathrm{~km}$ offshore 
and the ${ }^{131} \mathrm{I} /{ }^{137} \mathrm{Cs}$ ratios specific to the modelled zones of atmospheric deposition (Bailly du Bois et al., 2011). The direct liquid releases from FDNPP have a different signature compared with the atmospheric emissions, which reflects the physical and chemical processes occurring at the source of the releases, such as the leaching of corium by cooling water.

\subsection{Mapping zones of exceedance of the maximum permissible concentration (MPC) in fish}

The mapping of iso-concentration contours will also make it possible to delimit marine areas potentially concerned by exceedance of the maximum permissible concentration (MPC) of ${ }^{134} \mathrm{Cs}$ and ${ }^{137} \mathrm{Cs}$ in fish for marketing with a view to consumption (Fig. 4).

The MPC was fixed at $500 \mathrm{~Bq} \cdot \mathrm{kg}^{-1}$ by the Commission Implementing Regulation (EU) No. 351/2011 of 11 April 2011. In addition, a caesium concentration factor of 100 has been established for the consumable parts of fish (IAEA, 2004). This means that seawater having ${ }^{134} \mathrm{Cs}$ and ${ }^{137} \mathrm{Cs}$ concentrations in excess of $5 \mathrm{~Bq} . \mathrm{L}^{-1}$ would lead to a contamination of fish at around the MPC level. However, several other factors should be taken into account: (i) the results can vary over an order of magnitude because of the many environmental parameters that can influence the precision of the calculations; (ii) the estimates so obtained are only valid for a prolonged exposure to the same level of concentration in water. However, this is not the case for an accidental release of limited duration, leading to constantly evolving concentrations; (iii) many fish species migrate and can transit through the contaminated zones, but the duration is too short to allow equilibrium to be achieved with the concentrations of radionuclides in seawater.

By taking these factors into account, and assuming that the total release of ${ }^{134} \mathrm{Cs}+{ }^{137} \mathrm{Cs}$ (corresponding to $11.4 \times 10^{15} \mathrm{~Bq}$, as calculated in the previous section) disperses isotropically in the uppermost $100 \mathrm{~m}$ of the water column, the MPC could be exceeded within a radius of approximately $120 \mathrm{~km}$ around the FDNPP. This value serves only as an indication, given the drastic assumptions concerning the inputs of radioactivity into the marine environment, the processes of radionuclide transfer between the various compartments of the marine environment, the behaviour of fish and the dynamics of the water masses.

In an accident situation, the MPC-based approach is favourable to radioprotection, but leads to an overestimation of the exclusion zones by assuming steadystate conditions that will never be reached by the transient states observed in situ. To obtain results closer to reality, the dynamics of the water masses must be taken into account, as well as the kinetics of transfer of radionuclides to the biota. 


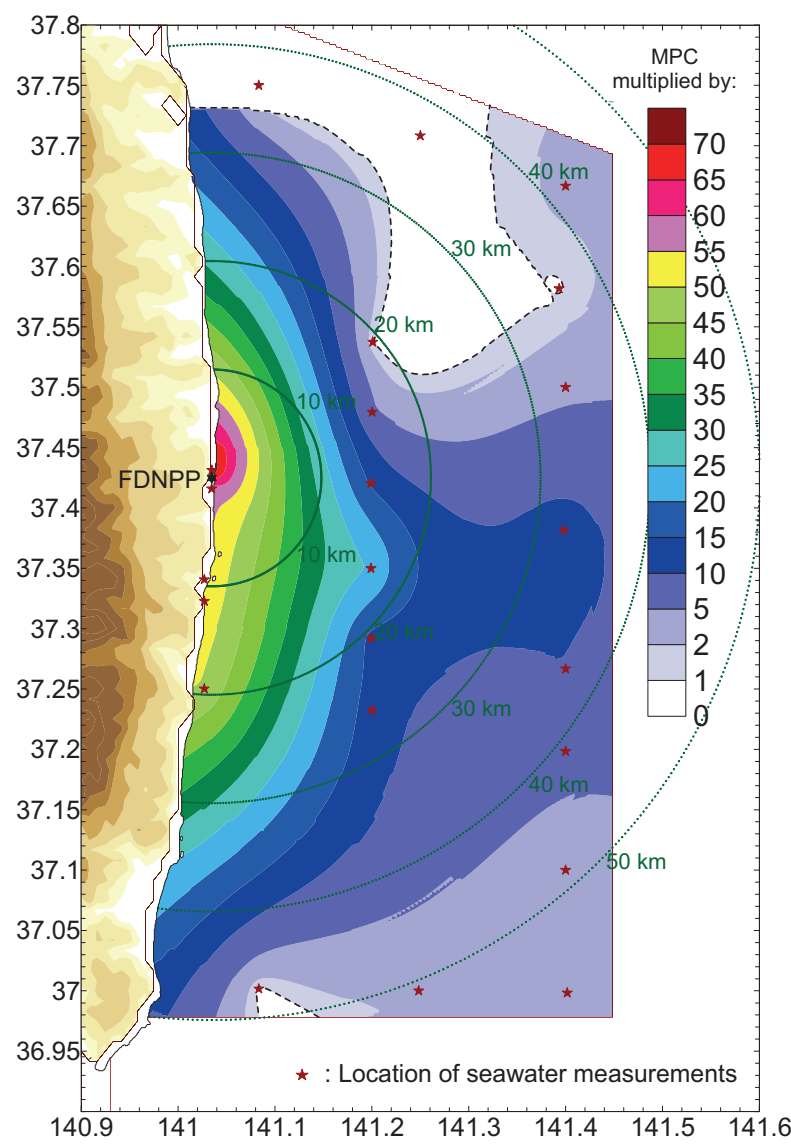

Figure 4 - Estimation of the exceedance of the maximum permissible concentration (MPC $=500 \mathrm{~Bq} \cdot \mathrm{kg}^{-1}$ dry matter according to the Commission Implementing Regulation (EU) No. 351/2011 of 11 April 2011) assuming a concentration factor CF for fish of 100 (IAEA, 2004) and based on the mean values of the concentrations in ${ }^{134} \mathrm{Cs}$ and ${ }^{137} \mathrm{Cs}$ (20-27 April 2011). The dotted line corresponds to a value of 1 .

\section{Phase 3: interpreting enriched statistical data during a stabilised release}

\subsection{Definition of phase 3 (29 April-31 October 2011)}

From 29 April 2011 onwards, the concentrations in seawater were controlled by dilution processes associated with renewal of the water masses. The characterisation of these processes led to a new estimation of the source term. This latter then 
could be injected into a hydrodynamic model, called M-3D (Model for Applications on a Regional Scale; Lazure and Dumas, 2008), which has been developed by Ifremer to model the dispersion of radionuclides off Japan.

This date also marked the beginning of the sampling of marine sediments. This stage is very important in terms of radioecology because sediments represent sinks and sources of radionuclides in the marine environment, owing to their capacity for adsorption and desorption of the radionuclides, as well as the presence of an organic fraction which is a resource for many phyla. These rather immobile sediments also represent a source reservoir of radionuclides, in particular close to the coasts where maritime activities are most developed. It is important to stress that, after penetrating inland by up to $10 \mathrm{~km}$ in places, the tsunami run-up was followed by a retreat that transported considerable amounts of natural and anthropic materials. The adsorption-desorption properties of such particles, as well as their mobility within the marine environment, are probably very different from the materials so far studied in radioecology, which are based on stabilised natural marine sediments.

This phase ended on 31 October 2011, after which the concentrations of radionuclides in seawater fell below the detection limits (i.e. approximately $20 \mathrm{~Bq} . \mathrm{L}^{-1}$ on average). The significant measurements obtained after 31 October 2011 (Fig. 1) required a special metrological effort by the Japanese organisations.

\subsection{Available data}

During this third phase, measurements were carried out by Japanese organisations on three types of samples: seawater, sediments and biota.

The intensity of efforts dedicated to seawater sampling reached a peak, with a coverage that was extended to approximately $100000 \mathrm{~km}^{2}$ (99.6\% of the samples were collected between longitudes $140.60^{\circ} \mathrm{E}$ and $144.02^{\circ} \mathrm{E}$, and latitudes $35.50^{\circ} \mathrm{N}$ and $38.68^{\circ} \mathrm{N}$ ). The monitoring stations defined in phase 1 were retained. In total, the number of sampling stations was multiplied by a factor of ten, with each of them providing more or less continuous temporal monitoring. The average number of daily samplings rose from 15 to 22 (29 April-31 October 2011), reaching a maximum of 29 (29 April-30 June 2011). There were more than 50 samplings on 10 dates during the third phase, with a maximum of 90 on 22 June 2011 (Fig. 1). A total of 4100 samples were collected by TEPCO, MEXT, and, to a lesser extent, by the University of Hokkaido ( $0.2 \%$ of samples) and the Prefecture of Fukushima (3\% of samples). From 29 April 2011, the measured concentrations of ${ }^{131} \mathrm{I}$, ${ }^{134} \mathrm{Cs}$ and ${ }^{137} \mathrm{Cs}$ in the samples were systematically lower than $1000 \mathrm{~Bq} \cdot \mathrm{L}^{-1}$, and only $10 \%$ of the samples collected over a 48 -hr period yielded ${ }^{137} \mathrm{Cs}$ concentrations 
higher than $100 \mathrm{~Bq} \cdot \mathrm{L}^{-1}$. The measurements carried out on the beta-emitting radionuclides (after 18 April 2011) primarily concerned ${ }^{89} \mathrm{Sr}$ and ${ }^{90} \mathrm{Sr}$, which are present at mean concentrations of 9 and $2 \mathrm{~Bq} . \mathrm{L}^{-1}$, respectively, in almost 30 of the analysed samples.

As regards the sediments, 234 samples (Fig. 1) were collected in a marine area comprised within the zone defined for seawater sampling, with an average water depth of $145 \mathrm{~m}$ (minimum: $24 \mathrm{~m}$; maximum: $675 \mathrm{~m}$ ). The stations used for collecting water and sediment samples do not always coincide. The radionuclides showing the highest concentrations are: ${ }^{131} \mathrm{I}$ (22 significant measurements; mean value of $\left.3280 \mathrm{~Bq} \cdot \mathrm{kg}^{-1}\right),{ }^{134} \mathrm{Cs}$ and ${ }^{137} \mathrm{Cs}$ ( 243 and 259 significant measurements, with mean values of 1325 and $1370 \mathrm{~Bq} \cdot \mathrm{kg}^{-1}$, respectively), followed by ${ }^{129} \mathrm{Te}$ and ${ }^{129 \mathrm{~m}} \mathrm{Te},{ }^{89} \mathrm{Sr}$ and ${ }^{90} \mathrm{Sr}$, and ${ }^{140} \mathrm{La}$, with concentrations ranging from 15 to $100 \mathrm{~Bq} \cdot \mathrm{kg}^{-1}$. The presence of ${ }^{129} \mathrm{Te}$ - which has a very short half-life (1.16 hours) - more than two months after the accident is explained by the fact that its parent isotope, ${ }^{129 \mathrm{~m}} \mathrm{Te}$, has a half-life of 33.6 days.

As mentioned above, these results of radionuclide concentration in seawater and sediments should be interpreted with caution, given the absence of information on the conditions of sampling, and the conditioning and treatment of the samples, as well as the techniques of counting employed. Moreover, as regards the sediments, the lack of information on the nature, granulometry, density and volumes collected makes it difficult to interpret the concentrations. It is merely specified that, in one case out of ten, the concentrations are expressed in kg dry matter. Lastly, the radionuclides are only contained within a thin layer of surface sediment. This surface layer is diluted in the bulk sediment sample, which could give rise to an underestimation of the concentrations.

During this second phase, 2400 samples of biota were collected in Japanese ports during the landing of fishery products (Fig. 1). As with phase 2, the absence of any information on the fishing zones, the conditions of sampling or the treatment of the samples, as well as the techniques of counting employed, make it difficult to interpret these data as they stand.

\subsection{Updating the source term}

The measurement campaign carried out by the Japanese organisations allowed the IRSN to update its estimate of the marine source term. The new adopted methodology is briefly described below (see Bailly du Bois et al., 2011, for more details). In particular, this method takes account of the renewal of water masses and the spatial variability of the thickness of the mixing layer inferred from salinitytemperature profiles carried out by MEXT in April 2011. The total quantities of ${ }^{137} \mathrm{Cs}$ contained in a water volume located near FDNPP, in which measurements 


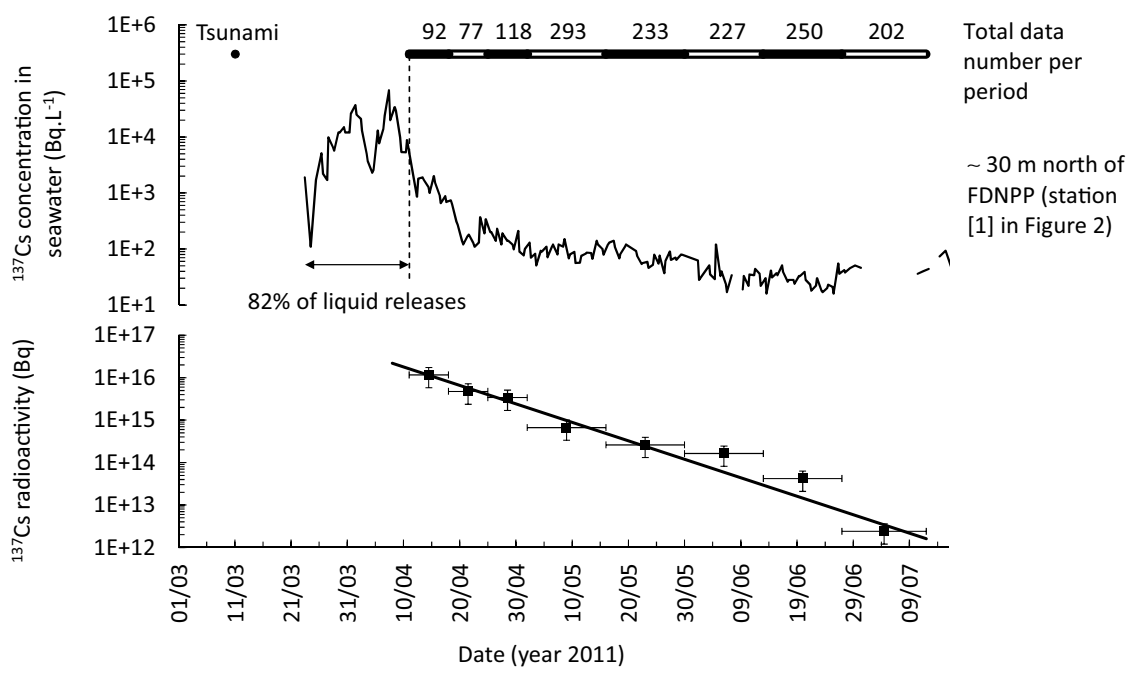

Figure 5 - Time evolution of the total inventory of ${ }^{137}$ Cs contained in a volume of water located near FDNPP between longitudes $140.90^{\circ} \mathrm{E}$ and $141.45^{\circ} \mathrm{E}$ and latitudes $36.93^{\circ} \mathrm{N}$ and $37.82^{\circ} \mathrm{N}$, with number of data points representing concentration of ${ }^{137} \mathrm{Cs}$ in seawater taken into account for each period of calculation.

of concentrations are particularly well documented (marine area of $5000 \mathrm{~km}^{2}$ located between longitudes $140.90^{\circ} \mathrm{E}$ and $141.45^{\circ} \mathrm{E}$ and latitudes $36.93^{\circ} \mathrm{N}$ and $37.82^{\circ} \mathrm{N}$ ), were calculated over contiguous periods between 11 April and 11 July 2011 (Fig. 5). Within each of these periods, between 92 and 293 measurements of ${ }^{137} \mathrm{Cs}$ concentration in seawater were taken into account. The results show that the total inventory of ${ }^{137} \mathrm{Cs}$ decreases with time according to an exponential law with a half-life of 6.9 days (confidence interval: 5.7-8.6 days) (Fig. 5). In other words, the quantity of ${ }^{137} \mathrm{Cs}$ contained in the studied volume decreases by half every 6.9 days. This dilution results from the characteristics of the ocean currents (Kuroshio and Oyashio) which converge in this zone, in particular their intensity and direction of propagation. These results corroborate and quantify the dilution scenario so far considered. The extrapolation of this dilution curve up to 8 April 2011 allows us to estimate a total ${ }^{137}$ Cs inventory of $22 \times 10^{15} \mathrm{~Bq}$ present in seawater at the end of the main period of release (26 March-8 April 2011). This new value of the source term may underestimate the real situation because it does not take into account the export of radionuclides from the studied volume due to the renewal of water before 8 April 2011. By adding a direct liquid release from FDNPP estimated at $5 \times 10^{15} \mathrm{~Bq}$ after April 8 (Bailly du Bois et al., 2011), the source term corresponding to direct liquid releases of ${ }^{137} \mathrm{Cs}$ can be reassessed as $27(12-41) \times 10^{15} \mathrm{~Bq}$. This estimate of the releases of ${ }^{137} \mathrm{Cs}$ to the sea is 4.7 times 
higher than the value initially calculated during phase 2. This new estimate is based on sampling over several months with a frequency and density adapted to the problem. The main error associated with this calculation is related to the estimation of the thickness of the mixing layer (Bailly du Bois et al., 2011). Two other methods can provide an assessment of the direct liquid releases from FDNPP. The first depends on the estimation of released water fluxes and high-frequency measurements of their radionuclide concentrations (NERH, 2011). This method is subject to strong uncertainties during the accident period because of the technical resources available, the potential occurrence of unforeseen releases and the hypotheses that are taken into account (diameter of a breach based on remote observations). The second method consists of reproducing the measured concentrations using a dispersion model (Kawamura et al., 2011; Tsunume et al., 2011). To reproduce the water renewal rate, this latter approach requires a hydrodynamic model previously validated by in situ measurements. The estimation of the source term is thus directly related to the representativity of the model.

\subsection{Physical modelling of dispersion}

In phase 3, the modelling of the dispersion of a given radionuclide at sea was made possible by knowledge of the source term and the water renewal rate, as well as by confronting the modelled and measured concentrations of radionuclides in seawater.

At the request of the IRSN, this modelling was carried out by Ifremer, developer of the MARS-3D computer code used routinely by the IRSN in metropolitan France. For this application, the model uses the boundary conditions of the Mercator-Ocean (currents) and $\mathrm{ECMWF}^{9}$ (winds) models. Figure 6 illustrates the simulation results obtained on the scale of the North-West Pacific. It highlights the complexity and variability of dispersion resulting from convergence between the Kuroshio and Oyashio currents. The confrontation of the simulated concentrations with values measured less than $1 \mathrm{~km}$ from FDNPP yields concordant results. On the scale of the North-West Pacific (Fig. 6), the data collected up to the end of July 2011 allow only a partial validation of the dispersion model, the sampled area being insufficiently large and/or the DLs of measurements being too high.

\subsection{Transfer of radioactivity to the sediments}

The whole set of measurements of ${ }^{137} \mathrm{Cs}$ concentrations in the sediments shows an average increasing trend with time. Two factors can explain this evolution: (i) the

\footnotetext{
9 ECMWF, http://www.ecmwf.int/.
} 


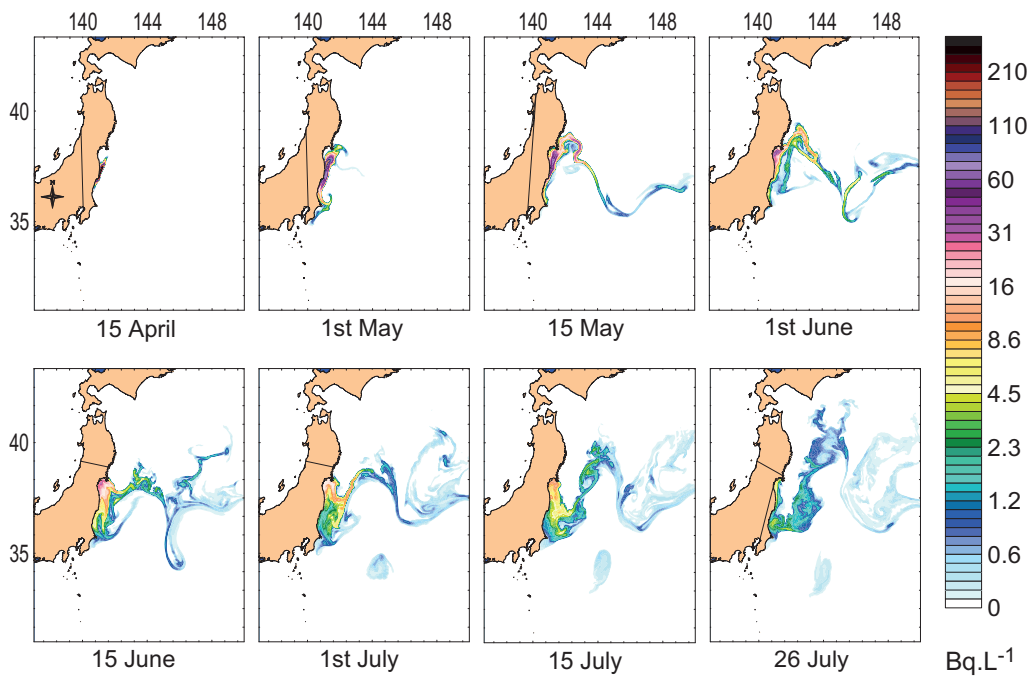

Figure 6 - Concentrations of ${ }^{137}$ Cs in seawater simulated by MARS-3D modelling between 15 April and 26 July 2011 in the North-West Pacific; Ifremer-IRSN results.

relatively slow kinetics of caesium transfer towards sedimentary particles, and (ii) the progressive deposition of the finest contaminated particles. However, this increase should be stabilised, taking into account the reduction of ${ }^{137} \mathrm{Cs}$ concentrations in seawater. Indeed, the transient pollution of water by ${ }^{137} \mathrm{Cs}$ clearly did not lead to the attainment of equilibrium according to the partition coefficient $K_{d}$.

In the long term, a fraction of the radionuclides fixed onto the sedimentary particles is likely to be remobilised towards the water column. In such a scenario, the sedimentary deposits behave as remote and diffuse sources that are time-delayed. However, the inventory of ${ }^{137} \mathrm{Cs}$ fixed onto the sediments appears relatively small and its release should not lead to a significant labelling of seawater. Studies in the Irish Sea indicate a period of two years for the release of caesium contained in the sediments (Finegan et al., 2009; Jones et al., 2007). Assuming a similar period for offshore FDNPP, the topmost $10 \mathrm{~cm}$ of sediment contaminated with $1000 \mathrm{~Bq} \cdot \mathrm{kg}^{-1}$ would supply $500 \mathrm{~Bq} \cdot \mathrm{dm}^{-2}$ to a 20 -m-thick layer of overlying water in two years (in the most unfavourable case). Taking into account the kinetics of water renewal mentioned in the previous section (50\% water renewed every 6.9 days), the concentrations produced in seawater would be lower than $50 \mathrm{mBq} . \mathrm{L}^{-1}$. These concentrations should not have any impact on radioprotection via the pelagic biota. On the other hand, the benthic and/or benthopelagic filter-feeders could be directly concerned by a residual pollution of the sediments. 


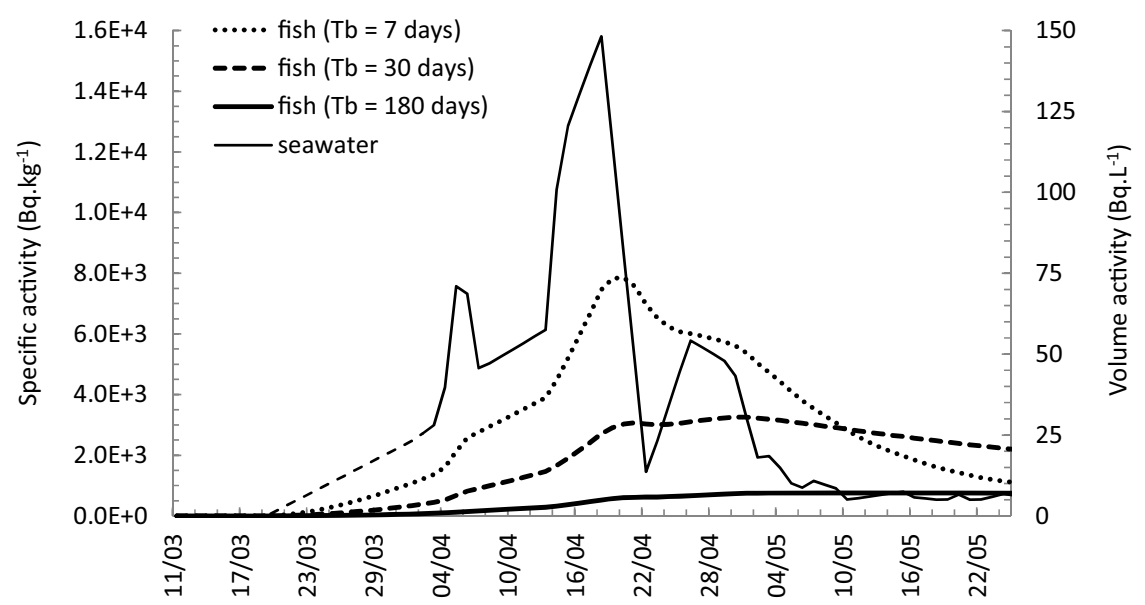

Figure 7 - Modelling results for the transfer of ${ }^{137}$ Cs from seawater to fish as a function of the biological half-life, Tb, of fish and the concentration of ${ }^{137} \mathrm{Cs}$ in seawater $15 \mathrm{~km}$ from the coast.

\subsection{Modelling the kinetics of transfer of radioactivity to fish}

Both the sediments and the seawater can be sources of contamination for the biota. When a marine organism comes into contact with a constant concentration of radionuclides in seawater, equilibrium is defined in terms of the $\mathrm{CF}$ and the rate of attainment of equilibrium (i.e. the transfer kinetics) is described by the biological half-life $(\mathrm{Tb})$. The shorter the $\mathrm{Tb}$, the more rapidly equilibrium is achieved. The longer the $\mathrm{Tb}$, the longer the time taken for the organism to become contaminated. This implies that contamination can be weak in migrating species that remain only a short time in the contaminated zone. In addition, contamination can reach equilibrium according to the $\mathrm{CF}$ in sedentary species if the concentrations in seawater are stable with time. When the radionuclide concentration in water decreases or the organism leaves the contaminated zone (carried by ocean currents or due to its own locomotion), the contamination persists at a similar rate to the depuration. Therefore, it appears that making estimates of contamination of the biota remains complex, especially in the absence of precise data on the marine species present after 11 March 2011 in the Pacific Ocean off Japan. A first approximation of the evolution of the ${ }^{137} \mathrm{Cs}$ concentration in living organisms such as fish was modelled (Fig. 7) by assuming: (i) three different Tb values (short: 7 days; long: 180 days; medium: 30 days), (ii) concentrations of ${ }^{137} \mathrm{Cs}$ in seawater measured $15 \mathrm{~km}$ off the coast (concatenation of data from stations [5] to [10], Fig. 2), (iii) a CF value of 100 (recommended value for fish in the case of caesium; IAEA, 2004), and (iv) several assumptions to compensate for the absence of seawater concentration data 


\section{CONSEQUENCES OF RADIOACTIVE RELEASES INTO THE SEA}

before 2 April 2011: 8 days' transit time for radionuclides between FDNPP and waters located $15 \mathrm{~km}$ off the coast, and linear increase in concentrations between 19 March and 2 April 2011. For more details on the model, see Fievet and Plet (2003). To a first approximation, the results indicate that the maximum concentration of ${ }^{137} \mathrm{Cs}$ in fish obtained with the shortest $\mathrm{Tb}$ (7 days) is consistent with the value of $7300 \mathrm{~Bq} \cdot \mathrm{kg}^{-1}$ measured by the Japanese authorities on 18 April 2011 on the Pacific sandlance Ammodytes personatus landed at the port of Iwaki.

\section{Conclusion}

In conclusion, the accident at FDNPP (March 2011) gave rise to the largest known single input rate of radionuclides into the marine environment stemming from a single source. These fluxes led to high concentrations of radionuclides in seawater, living species and sediments. These concentrations will remain measurable for several years near the coasts and on the scale of the North Pacific.

The IRSN was able to construct scenarios for the dispersion of radionuclides in seawater and define a method for estimating the source term, as well as the orders of magnitude of the transfers of radionuclides to the biota and sediments. The collection of data on the concentration of radionuclides in the marine environment by Japanese organisations (TEPCO, MEXT, Prefecture of Fukushima and University of Hokkaido) and their communication to the international community played a crucial role in characterising the in situ processes. Indeed, since the formulation of the hypotheses depended on the data available, the scenarios and estimates of the IRSN evolved while being supported by a daily-updated data bank. The processes were thus perceived in a transitory manner. Three phases are highlighted according to the nature and volume of the data available: from 11 to 20 March, from 21 March to 28 April and from 29 April to 31 October 2011.

At the end of the three phases described here, it became necessary to understand, both in detail and in the long term, the mechanisms of dispersion and transfer of radionuclides to the biota and sediments. Several lines of discussion are now envisaged. For example, the history of the inputs of radionuclides to the marine environment can be assessed by reverse modelling. These studies imply continuing with the collection and interpretation of the data. The detection limits of the counting techniques carried out by TEPCO in routine analyses have been lowered since November 2011 (Fig. 1). These new data make it possible to envisage regular and significant measurements in the long term. Episodically, oceanographic campaigns will be able to supplement this database (Honda et al., 2012), since techniques used classically in oceanography lead to DLs lower than $10^{-3} \mathrm{~Bq} . \mathrm{L}^{-1}$. The concentrations in sediments must also be measured regularly. From now on, sediments represent the main source of radionuclides near the coast owing to the processes of desorption and resuspension as well as the sedimentation 
of particles derived from river catchments (including the potential occurrence of "hot" particles). Lastly, as regards the biota, ecological and physiological studies should be carried out on the species present in the impacted zones. The state of the biota following the passage of the tsunami is as yet unknown. In particular, the food chains and transfer kinetics will need to be characterised.

Apart from being used in environmental monitoring, this set of concentration measurements will allow us to assess the ability of computer codes to reproduce not only dispersion observed on a large scale, but also transfers to the biota and sediments. This could be carried out by iterative comparisons between the modelled and measured concentrations, by taking account of the speciation of the radionuclides. In addition, this data set will make it possible to characterise or reassess the physical and biological processes. For example, the ratio of the concentrations of ${ }^{134} \mathrm{Cs}$ and ${ }^{137} \mathrm{Cs}$ provides a tool for tracing water masses on the scale of the Pacific Ocean.

The review of the accident at FDPP highlights the need for rapid modelling of the fate of radioactive releases, in order to: (i) delimit maritime exclusion zones according to the criteria of intervention, and then (ii) estimate the concentrations of radionuclides in the various matrices making up the marine environment with a view to calculating the dose to humans. Such a model could also be used as a decision-making aid to manage exploitation of the marine environment, to test possible countermeasures and assess dosimetric impacts. The operational modelling implemented here implies being aware of the uncertainties associated with the applied tools. As a prerequisite, this would involve efforts to validate the models and qualify the forcing data used.

Finally, the chronology of the events shows that it is necessary to carry out measurements on samples collected at the earliest opportunity and as close as possible to the damaged site, so as to characterise the source term in the best possible way and predict its impact (input data for models). In such a context, it would be appropriate to study the use of special instruments (autonomous sampling or measurement systems using moored or drifting instrumented buoys).

Acknowledgements. The authors thank the Japanese scientists who collected samples under difficult conditions and placed the results of their measurements at the disposal of the international community. The authors also thank the personnel of the Emergency Response Centre and the Marine Support Unit of the IRSN, as well as Tina Odaka for the collection of these data. Michael Carpenter translated the original French text, and assisted with editing of the English. 


\section{CONSEQUENCES OF RADIOACTIVE RELEASES INTO THE SEA}

\section{REFERENCES}

Aoyama M., Hirose K. (2003) Temporal variation of ${ }^{137}$ Cs water column inventory in the North Pacific since the 1960s, J. Environ. Radioact. 69, 07-117.

Bailly du Bois P., Laguionie P., Boust D., Korsakissok I., Didier D., Fiévet B. (2011) Estimation of marine source-term following Fukushima Dai-ichi accident, J. Environ. Radioact., doi:10.1016/j.jenvrad.2011.11.015.

Buesseler K., Aoyama M., Fukasawa M. (2011) Impacts of the Fukushima nuclear power plants on marine radioactivity, Environ. Sci. Technol. 45, 9931-9935.

Fievet B., Plet D. (2003) Estimating biological half-lifes of radionuclides in marine compartments from environmental time-series measurements, J. Environ. Radioact. 65, 91-107.

Finegan P., Vintró L.L., Mitchell P.I., Boust D., Gouzy A., Kershaw P.J., Lucey J.A. (2009) Accumulation, solid partitioning and remobilisation of 99Tc in subtidal and intertidal sediments in the Irish Sea, Cont. Shelf Res. 29, 1995-2010.

Fukushima Prefecture (2011) http://wwwcms.pref.fukushima.jp/pcp_portal/PortalServlet?DISPLAY_ ID=DIRECT\&NEXT_DISPLAY_ID=U000004\&CONTENTS_ID=24194.

Garnier-Laplace J., Beaugelin-Seiller K., Hinton T. (2011) Fukushima Wildlife Dose Reconstitution Signals Ecological Consequences, Environ. Sci. Technol. 45, 5077-5078.

Hokkaido University (2011) http://geos.ees.hokudai.ac.jp/eesatom/index.html\#h.

Honda M.C., Aono T., Aoyama M., Hamajima Y., Kawakami H., Kitamura M., Masumoto Y., Miyazawa Y., Takigawa M., Saino T. (2012) Dispersion of artificial caesium-134 and -137 in the western North Pacific one month after the Fukushima accident, Geochem. J. 46, 1-9.

IAEA (2004) Sediment distribution coefficients and concentration factors for biota in the marine environment, Technical Report Series 422, 1-95.

IRSN (2011a) Impact on marine environment of radioactive releases resulting from the FukushimaDai-ichi nuclear accident, 4th April 2011, IRSN Report.

IRSN (2011b) Impact on the marine environment of radioactive releases following the nuclear accident at Fukushima Dai-ichi, 13 May 2011, IRSN Report.

Jones D.G., Kershaw P.J., McMahon C.A., Milodowski A.E., Murray M., Hunt G.J. (2007) Changing patterns of radionuclide distribution in Irish Sea subtidal sediments, J. Environ. Radioact. 96, 63-74.

Kawamura H., Kobayashi T., Furuno A., In T., Iishikawa Y., Nakayama T., Shima S., Awaji T. (2011) Preliminary Numerical Experiments on Oceanic Dispersion of ${ }^{131} \mathrm{I}$ and ${ }^{137} \mathrm{Cs}$ Discharged into the Ocean because of the Fukushima Daiichi Nuclear Power Plant Disaster, J. Nucl. Sci. Technol. 48, 1349-1356.

Lazure P., Dumas F. (2008) An External-internal Mode Coupling for a 3D Hydrodynamical Model for Applications at Regional Scale (MARS), Adv. Water Resour. 31, 233-250.

NERH (2011) Report of Japanese Government to the IAEA Ministerial Conference on Nuclear Safety - The Accident at TEPCO's Fukushima Nuclear Power Stations, NERH Report.

Povinec P.P., Aarkrog A., Buesseler K.O., Delfanti R., Hirose K., Hong G.H., Ito T., Livingston H.D., Nies H., Noshkin V.E., Shima S., Togawa O. $(2005){ }^{90} \mathrm{Sr},{ }^{137} \mathrm{Cs}$ and ${ }^{239,240} \mathrm{Pu}$ concentration surface water time series in the Pacific and Indian Oceans - WOMARS results, J. Environ. Radioact. 81, 63-87.

Sanchez-Cabeza J., Levy I., Gastaud J., Eriksson M., Osvath I., Aoyama M. (2011) Transport of North Pacific ${ }^{137}$ Cs labeled waters to the south-eastern Atlantic Ocean, Progr. Oceanogr. 89, 31-37.

Schiermeier Q. (2011) Radiation Release Will Hit Marine Life, Nature 472, 145-146.

Tsumune D., Tsubono T., Aoyama M., Hirose K. (2011) Distribution of oceanic ${ }^{137}$ Cs from the Fukushima Daiichi Nuclear Power Plant simulated numerically by a regional ocean model, J Environ. Radioact., in press doi:10.1016/j.jenvrad.2011.10.007. 